\title{
On mentorship
}

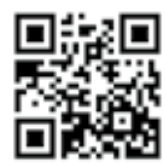

$\therefore$ we do not choose to be a mentor, others choose us. Your actions are being watched by others. ${ }^{\text {'[1] }}$

'No written word, no spoken plea,

Can teach youth what they should be.

Nor all the books on all the shelves

It's what the teachers are themselves. ${ }^{\text {[I] }}$

I have been fortunate to have had powerful mentors and role models throughout my career. Echoing the quotes above, none ever knew that I had chosen them! By their presence and performance in my daily working life (in and out of working hours), I judged them to be worthy mentors and my career was undoubtedly shaped by that observance.

I was reminded of this importance of mentorship while reading Adam Habib's South Africa's Suspended Revolution. ${ }^{[2]}$ In offering a partial explanation for our country's rash of service delivery protests, he explains that the Growth, Employment and Redistribution (GEAR) Strategy, requiring cuts in state expenditure and a reduction in the numbers of state employees, 'circumvented the transfer of skills and capacity that demanded the two distinct processes of training and mentorship. The skills transfer process was thus - his word 'sabotaged' ${ }^{[2]}$

Staff serving in public sector hospitals and clinics, linked as these are to South Africa's medical schools, are key to mentorship of the younger under- and postgraduate members of our profession. Which brings me to the matter of remunerated work outside the public service (RWOPS), which has featured in past issues ${ }^{[3,4]}$ and features again in the pages of this journal. ${ }^{[5]}$

As has been and is being pointed out, ${ }^{[4-6]}$ RWOPS is a dispensation for all public servants with rare skills, and is aimed within the health profession at improving remuneration for state-employed doctors. Controversial since its inception, RWOPS, as confirmed by the leadership of the South African Medical Association, ${ }^{[6]}$ 'had a purpose nevertheless - the retention of specialist skills in the public sector,', and thus to ensure provision of services to patients and assure teaching and training of medical students and trainee specialists.

Caldwell[ ${ }^{[7]}$ alerted us to the presence of miscreants abusing RWOPS, calling them 'thieves of the state' in the SAMJ's correspondence columns; he continues to beat that drum.

There are abuses of the system, amply documented by Bateman ${ }^{[8]}$ (see also Taylor and $\mathrm{Khan}^{[5]}$ ), by some doctors who spend unreasonable amounts of time treating private patients and neglecting their public service obligations. This led to the Minister of Health's statement that 'patients are dying because of specialist greed. ${ }^{[8]}$ More significantly, the absence of colleagues from the wards, clinics, operating theatres and tutorial rooms while they pursue RWOPS leads also to failure of mentorship - 'there is no or very limited teaching from those who have a lot to share. ${ }^{[8]}$ And since, as the opening quote suggests, mentees 'watch the teachers themselves, ${ }^{[1]}$ they will be encouraged to believe that they may operate with impunity in their own professional practice, as Caldwell's colleagues allegedly do.

Moreover, as a result of abuses of RWOPS, those colleagues who are left behind to 'hold the public fort' become 'overloaded, angry and resentful: ${ }^{[8]}$

It bears noting that according to the surveys reported by Taylor and Khan, ${ }^{[5]}$ colleagues, including trainees, believe RWOPS to be beneficial: ensuring maintenance of skills, offering additional financial reward, and affording a spectrum of patients/diseases different from that encountered in the public sector and exposure to operations not routinely performed in public hospitals. This is resonant of claims that lack of surgical training for junior doctors at some hospitals has little to do with RWOPS. Instead the reduced number of lists, and therefore cases, has meant that trainees receive less surgical training. As a 'knock on', senior registrars have to do more surgery to try to increase their exposure, further reducing training for juniors. ${ }^{[8]}$

As Taylor and Khan indicate, ${ }^{[5]}$ 'A national policy is required that complies with appropriate public service regulations. The framework should set out the responsibilities of staff with regard to their public service commitments, the restrictions pertaining to private work, and how public sector and private sector duties will be monitored. This framework will require flexibility if it is to apply to all provinces and institutions, as service loads and requirements to conduct research or teach will vary between hospitals.'

The original intent of RWOPS remains valid. It is important to retain the skills of experienced staff in the public sector, and RWOPS

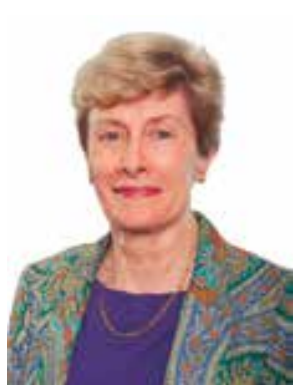
helps to do this. However, it should be permitted to continue only if public sector work is competently dealt with and remains the primary responsibility of public sector doctors. The key to achieving this is strong management to enforce a fair RWOPS policy.

\section{Janet Seggie}

Editor

janet.seggie@hmpg.co.za

1. John Wooden, UCLA Bruins' Baseball Coach. Insights on Teaching Excellence from Coach John Wooden. http://www.paulbuyer.com/4-insights-on-teaching-excellence-from-coach-john-wooden/ (accessed 19 April 2014)

2. Habib A. South Africas's Suspended Revolution. Johannesburg: Wits University Press, 2013:65-66. 3. Bateman C. RWOPS clampdown - a crisis in the offing. S Afr Med J 2013;103(6):354. [http://dx.doi. org/10.7196/SAMJ.7008]

Bateman C. RWOPS abuse 'eroding ethical standards of juniors'. S Afr Med J 2013;106(8):505-506. [http://dx.doi.org/10.7196/SAMJ.7165]

Taylor A, Khan D. The RWOPS debate - yes we can! S Afr Med J 2014;104(7):475-477. [http://dx.doi. org/10.7196/SAMJ.8050]

6. Grootboom M, Sonderup M, Ramathuba P. Thieves of the state and the South African Medical Association (SAMA): The South African Medical Association responds. S Afr Med J 2013;103(6):354. [http://dx.doi.org/10.7196/SAMJ.7008]

7. Caldwell RM. Thieves of the state and the South African Medical Association (SAMA). S Afr Med J . Caldwell RM. Thieves of the state and the South African
2013;103(6):354. [http://dx.doi.org/10.7196/SAMJ.7008]

8. Bateman C. RWOPS abuse - Government's had enough. S Afr Med J 2012;102(12):899-901. [http:// Bateman C. RWOPS abuse - Go
dx.doi.org/10.7196/SAMJ.6481]

S Afr Med J 2014;104(7):453. DOI:10.7196/SAMJ.8437 